\title{
Anesthetic considerations for patients with esophageal achalasia undergoing peroral endoscopic myotomy: a retrospective case series review
}

\section{Considérations anesthésiques pour la prise en charge des patients atteints d'achalasie de l'œesophage subissant une myotomie per-orale endoscopique: compte rendu rétrospectif d'une série de cas}

\author{
Benjamin Löser, MD • Yuki B. Werner, MD • Mark A. Punke, MD • Bernd Saugel, MD • \\ Sebastian Haas, MD • Daniel A. Reuter, MD • Oliver Mann, MD • Anna Duprée, MD • \\ Guido Schachschal, MD • Thomas Rösch, MD • Martin Petzoldt, MD \\ Received: 24 February 2016/Revised: 25 November 2016/ Accepted: 4 January 2017/Published online: 23 January 2017 \\ (C) Canadian Anesthesiologists' Society 2017
}

\begin{abstract}
Purpose Peroral endoscopic myotomy (POEM) is a novel technique for treating esophageal achalasia. During POEM, carbon dioxide $\left(\mathrm{CO}_{2}\right)$ is insufflated to aid surgical dissection, but it may inadvertently track into surrounding tissues, causing systemic $\mathrm{CO}_{2}$ uptake and tension capnoperitoneum. This in turn may affect cardiorespiratory function. This study quantified these cardiorespiratory effects and treatment by hyperventilation and percutaneous abdominal needle decompression (PND).

Methods One hundred and seventy-three consecutive patients who underwent POEM were included in this four-year retrospective study. Procedure-related changes in peak inspiratory pressure $\left(p_{\max }\right)$, end-tidal $\mathrm{CO}_{2}$ levels
\end{abstract}

B. Löser, MD ( $₫) \cdot$ M. A. Punke, MD · B. Saugel, MD .

S. Haas, MD - D. A. Reuter, MD - M. Petzoldt, MD

Department of Anesthesiology, Center of Anesthesiology and Intensive Care Medicine, University Medical Center Hamburg-

Eppendorf, Martinistrasse 52, 20251 Hamburg, Germany

e-mail: B.Loeser@uke.de

Y. B. Werner, MD · G. Schachschal, MD · T. Rösch, MD Department of Interdisciplinary Endoscopy, University Medical Center Hamburg-Eppendorf, Hamburg, Germany

O. Mann, MD · A. Duprée, MD

Department of General, Visceral and Thoracic Surgery, University Medical Center Hamburg-Eppendorf, Hamburg, Germany $\left(\right.$ et $\left.\mathrm{CO}_{2}\right)$, minute ventilation $(\mathrm{MV})$, mean arterial pressure $(M A P)$, and heart rate (HR) were analyzed. We also quantified the impact of PND on these cardiorespiratory parameters.

Results During the endoscopic procedure, cardiorespiratory parameters increased from baseline: $p_{\max } 15.1$ (4.5) vs 19.8 (4.7) $\mathrm{cm} \mathrm{H}_{2} \mathrm{O}$; et $\mathrm{CO}_{2} 4.5$ (0.4) vs 5.5 (0.9) $\mathrm{kPa}[34.0$ (2.9) vs 41.6 (6.9) $\mathrm{mmHg}$; $\mathrm{MAP} 73.9$ (9.7) vs 99.3 (15.2) $\mathrm{mmHg}$; HR 67.6 (12.4) vs 85.3 (16.4) min $^{-1}(P<0.001$ for each $)$. Hyperventilation [MV 5.9 (1.2) vs 9.0 (1.8) $\left.L \cdot \mathrm{min}^{-1}, P<0.001\right]$ was applied to counteract iatrogenic hypercapnia. Individuals with tension capnoperitoneum treated with PND $(n=55)$ had higher peak $p_{\text {max }}$ values [22.8 (5.7) vs 18.4 (3.3) $\mathrm{cm} \mathrm{H}_{2} \mathrm{O}, P$ $<0.001]$ than patients who did not require PND. After $P N D, p_{\max }\left[22.8\right.$ (5.7) vs 19.9 (4.3) $\left.\mathrm{cm} \mathrm{H}_{2} \mathrm{O}, \mathrm{P}=0.045\right]$ and MAP [98.2 (16.3) vs 88.6 (11.8) $\mathrm{mmHg}, P=0.013]$ decreased. Adverse events included pneumothorax $(n=1)$, transient myocardial ischemia $(n=1)$, and subcutaneous emphysema ( $n=49)$. The latter precluded immediate extubation in eight cases. Postanesthesia care unit (PACU) stay was longer in individuals with subcutaneous emphysema than in those without $[74.9 \mathrm{~min}$ (34.5) vs 61.5 (26.8 $\mathrm{min}$ ), $P=0.007]$.

Conclusion Carbon dioxide insufflation during POEM produces systemic $\mathrm{CO}_{2}$ uptake and increased intraabdominal pressure. Changes in cardiorespiratory parameters include increased $p_{\max }$, et $\mathrm{CO}_{2}, \mathrm{MAP}$, and HR. Hyperventilation and PND help mitigate some of these changes. Subcutaneous emphysema is common and may delay extubation and prolong PACU stay. 


\section{Résumé}

Objectif La myotomie per-orale endoscopique (POEM) est une technique innovatrice pour le traitement de l'achalasie de l'oesophage. Pendant une POEM, on insuffle du dioxyde de carbone $\left(\mathrm{CO}_{2}\right)$ afin de favoriser la dissection chirurgicale, mais le $\mathrm{CO}_{2}$ peut accidentellement s'immiscer dans les tissus environnants, provoquant une accumulation systémique de $\mathrm{CO}_{2}$ et un capnopéritoine de tension, lequel pourrait, à son tour, potentiellement affecter la fonction cardiorespiratoire. Cette étude a quantifié ces effets cardiorespiratoires ainsi que le traitement par hyperventilation et une décompression abdominale percutanée à l'aiguille.

Méthode Cent soixante-dix-sept patients consécutifs ayant subi une POEM ont été inclus dans cette étude rétrospective d'une durée de quatre ans. Les changements liés à l'intervention suivants ont été analysés : la pression inspiratoire maximale $\left(p_{\max }\right)$, les taux de $\mathrm{PCO}_{2}$ de fin d'expiration $\left(\mathrm{PCO}_{2}\right)$, la ventilation minute (VM), la tension artérielle moyenne (TAM) et la fréquence cardiaque (FC). Nous avons également quantifié l'impact de la décompression abdominale percutanée à l'aiguille sur ces paramètres cardiorespiratoires.

Résultats Pendant l'intervention endoscopique, les paramètres cardiorespiratoires ont augmenté par rapport aux valeurs de base : $p_{\max } 15,1(4,5)$ vs $19,8(4,7) \mathrm{cm} \mathrm{H}_{2} \mathrm{O}$; $\mathrm{PCO}_{2} 4,5(0,4)$ vs 5,5 $(0,9) \mathrm{kPa}[34,0(2,9)$ vs 41,6 $(6,9)$ mmHg]; TAM 73,9 (9,7) vs 99,3 (15,2) $\mathrm{mmHg}$; FC 67,6 $(12,4)$ vs 85,3 (16,4) $\min ^{-1}(P<0,001$ pour chaque paramètre). On a appliqué une hyperventilation [VM 5,9

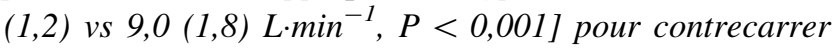
l'hypercapnie iatrogénique. Les personnes ayant un capnopéritoine de tension et traitées par décompression abdominale percutanée à l'aiguille ont affiché des valeurs maximales $p_{\max }$ plus élevées $[22,8(5,7)$ vs $18,4(3,3) \mathrm{cm}$ $\left.\mathrm{H}_{2} \mathrm{O}, \mathrm{P}<0,001\right]$ que les patients qui n'ont pas eu besoin de cette intervention. Après la décompression, la $p_{\max }[22,8$ $(5,7)$ vs $\left.19,9(4,3) \mathrm{cm} \mathrm{H}_{2} \mathrm{O}, \mathrm{P}=0,045\right]$ et la TAM [98,2 $(16,3)$ vs 88,6 $(11,8) \mathrm{mmHg}, P=0,013]$ ont baissé. Parmi les complications observées, citons un pneumothorax $(n=$ $1)$, une ischémie myocardique transitoire $(n=1)$, et un emphysème sous-cutané $(n=49)$. Cette dernière complication a empêché l'extubation immédiate dans huit cas. La durée du séjour en salle de réveil était plus longue pour les patients ayant souffert d'un emphysème sous-cutané que pour ceux n'en ayant pas eu [74,9 $\min (34,5)$ vs 61,5 (26,8 $\min ), P=0,007]$.

Conclusion L'insufflation de dioxyde de carbone pendant une POEM produit une accumulation systémique de $\mathrm{CO}_{2}$ et une augmentation de la pression intra-abdominale. Les changements au niveau des paramètres cardiorespiratoires comprenaient une augmentation de la $p_{\max }$, du $\mathrm{PCO}_{2}$, de la
TAM et de la FC. L'hyperventilation et la décompression abdominale percutanée à l'aiguille ont aidé à mitiger certains de ces changements. L'emphysème sous-cutané est une complication fréquente et pourrait retarder l'extubation et prolonger le séjour en salle de réveil.

Esophageal achalasia is a motility disorder characterized by dysfunction of the lower esophageal sphincter due to incomplete muscle relaxation. The standard treatment options include balloon dilatation and surgical myotomy using a laparoscopic approach (Heller myotomy). ${ }^{1-3}$

A purely endoscopic approach, peroral endoscopic myotomy (POEM), is a recently developed, less-invasive treatment for achalasia $^{4}$ that has been shown to be effective. ${ }^{5-11}$ POEM is performed via endoscopic mucosal entry into, and a submucosal tunnel within, the gastrointestinal wall (Figure). The inner circular muscle bundles of the lower esophageal sphincter are dissected while preserving the outer longitudinal muscle. To facilitate the dissection, carbon dioxide $\left(\mathrm{CO}_{2}\right)$ is insufflated via the endoscope, but it may inadvertently escape into the surrounding tissues via artificially created passages, tracking into the mediastinum and abdomen. Consequences include subcutaneous emphysema, capnomediastinum, capnoperitoneum, and pneumothorax, which could compromise cardiorespiratory function. ${ }^{10,12-14}$ Hyperventilation may be helpful for reducing the systemic $\mathrm{CO}_{2}$ uptake. Percutaneous abdominal needle decompression (PND) may be necessary to decrease elevated abdominal pressure as a consequence of tension capnoperitnoneum. ${ }^{15}$

Although it is recognized that POEM poses unique anesthesia-related challenges, standard approaches have yet to be established. Moreover, complications associated with POEM are inconsistently described and variably defined. ${ }^{5,10,11}$ The aim of this study was to quantify POEMrelated changes in cardiorespiratory parameters and to determine whether PND can effectively improve compromised cardiorespiratory function in patients with tension capnoperitoneum.

\section{Methods}

The Ethics Committee of the Medical Board of Hamburg, Germany approved this retrospective single-centre study (WF-072/13). Medical records of consecutive patients who underwent POEM for motility disorders of the esophagus at the University Medical Center Hamburg-Eppendorf between June 2010 and June 2014 were reviewed. 

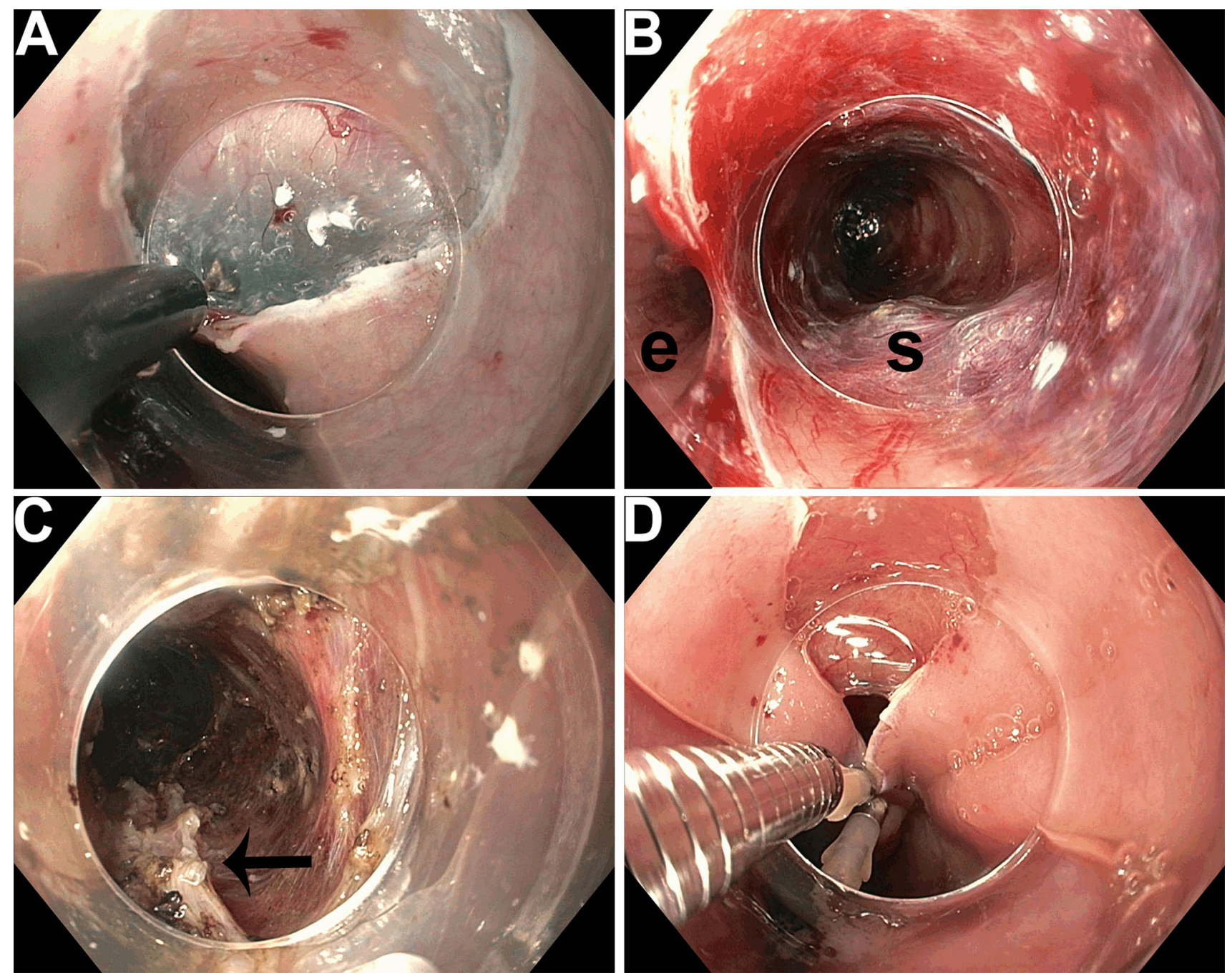

Figure Peroral endoscopic myotomy procedure: (A) Mucosal entry to the submucosal space. After injection of saline and methylene blue, a 2-cm longitudinal mucosal incision is made in a right lateral position at the level of the mid-esophagus. (B) Submucosal tunnel ( $\mathrm{s}=$ entry in the submucosal tunnel; $\mathrm{e}=$ esophageal lumen). Endoscopic submucosal dissection is used for tunneling downward to the lesser

Electronically stored data, including anesthesia charts, were obtained from Soarian ${ }^{\mathrm{TM}}$ Health Archive (Release 3.04 SP12; Siemens Healthcare, Erlangen, Germany), Medlinq $^{\mathrm{TM}}$ Anaesthesie (Medlinq Softwaresysteme $\mathrm{GmbH}$, Hamburg, Germany), and the Endobase $^{\mathrm{TM}}$ Documentation System (Release 12.0; Olympus, Tokyo, Japan).

\section{Anesthesia and surgery}

Patients were prepared for POEM according to institutional standards, as described previously. ${ }^{7}$ A liquid diet was instituted for two to five days prior to surgery, and patients were kept nil per os overnight (for at least eight hours curvature of the gastric cardia. (C) Submucosal tunnel after selective myotomy of the circular muscle fibres (black arrow) over a length of approximately $6-15 \mathrm{~cm}$ starting $3 \mathrm{~cm}$ distal to the initial mucosal entry and extended until $2-3 \mathrm{~cm}$ beyond the gastroesophageal junction. (D) Closure of the mucosal entry site with standard endoscopic clips

before induction of anesthesia). In all patients, esophagogastroduodenoscopy was performed one day before POEM to remove food remnants from the esophagus. $^{7}$ All patients were treated perioperatively with a dose of $80 \mathrm{mg}$ of pantoprazole (starting from the day before POEM) and antibiotic prophylaxis. ${ }^{7}$ All procedures were performed in our endoscopy unit in a specialized endoscopy suite.

No standardized anesthesia protocol was implemented during the study period, with its management left to the discretion of the anesthesiologist. However, the following generalizations can be made. Procedures were performed under general anesthesia that typically included rapid sequence induction followed by orotracheal intubation. All 
individuals received a single dose of a neuromuscular blocking agent to facilitate endotracheal intubation. Muscle paralysis was not maintained throughout the procedure. General anesthesia was maintained by standard inhalational and/or intravenous anesthetic drugs. Cuffed reinforced endotracheal tubes (Woodbridge type; Mallinckrodt Lo-Contour ${ }^{\mathrm{TM}}$, Covidien, Dublin, Ireland) - internal diameter $7.5-8.5 \mathrm{~mm}$ for men and $7.0-7.5 \mathrm{~mm}$ for women - were used to avoid kinking or obstruction of the endotracheal tube during endoscopy. To prevent interference with the gastroscope, the endotracheal tube was positioned in the right lateral angle of the mouth and taped independently from the endoscopy mouthpiece. Of note, we did not use endotracheal tubes with subglottic evacuation ports and a suction lumen, as has been used in other studies. ${ }^{16}$ Patients were positioned supine on the endoscopy table with the head elevated $30^{\circ}$ and arms tucked. The abdomen was left exposed to assist in identifying and treating capnoperitoneum (below). Patients were subjected to volume-controlled mechanical ventilation with an oxygen/air mixture. $\mathrm{N}_{2} \mathrm{O}$ was never used. Initial ventilation parameters (tidal volume 6-8 $\mathrm{mL} \cdot \mathrm{kg}^{-1}$, respiratory rate $10-16$ breaths $\cdot \mathrm{min}^{-1}$, positive end-expiratory pressure $3-8 \mathrm{~cm}_{2} \mathrm{O}$ ) were adjusted to achieve normocapnia prior to commencement of endoscopy [end-tidal $\mathrm{CO}_{2}\left(\mathrm{etCO}_{2}\right)$ values of $4.0-6.0 \mathrm{kPa}$ $(30-45 \mathrm{mmHg})]$. Standardized monitoring consisted of three-lead electrocardiography, oscillometric noninvasive blood pressure (NIBP) monitoring, side-stream capnography, and pulse oximetry. Invasive cardiovascular monitoring was not routinely employed, and the decision was left to the discretion of the anesthesiologist as per the patient's underlying medical state.

Peroral endoscopic myotomy was performed as described previously ${ }^{4,6,7}$ using GIF HQ $180 / 190^{\mathrm{TM}}$ gastroscopes (Olympus, Tokyo, Japan). This consisted of A) an initial mucosal incision, B) submucosal endoscopic tunneling, C) selective myotomy of the circular muscle fibres, and D) closure of the mucosal entry (Figure). ${ }^{4,7}$ For POEM, $\mathrm{CO}_{2}$ insufflation via the endoscope is required for esophageal and tissue distension. Carbon dioxideinsufflation was provided via an $\mathrm{UCR}^{\mathrm{TM}} \mathrm{CO}_{2}$ insufflator (Olympus, Tokyo, Japan) with a preset $\mathrm{CO}_{2}$ flow of 1.2 $\mathrm{L} \cdot \mathrm{min}^{-1}$, which could be intermittently released, on demand, via fingertip control.

\section{Endpoints}

Patient records were assessed for the following items:

Patient characteristics including age, sex, American Society of Anesthesiologists classification, body mass index, significant co-morbidities, and the Eckardt symptom score. ${ }^{17}$ Information was also sought concerning duration of the anesthesia and the endoscopic procedure. Achalasia subtypes were classified using the Chicago Classification Criteria, which are based on high-resolution esophageal manometry findings. ${ }^{18}$

Procedure-related respiratory parameters [peak inspiratory pressure $\left(\mathrm{p}_{\max }\right)$, etCO $\mathrm{CO}_{2}$ levels, minute ventilation (MV)] and cardiovascular parameters [mean arterial pressure (MAP) and heart rate (HR)] were measured at several points during the procedure. Baseline values were recorded prior to POEM (after induction of general anesthesia, they were the last values recorded prior to endoscopy). Peak values were recorded during POEM (from mucosal incision until re-closure) and prior to and after PND (below). Baseline and peak values represent single measurements. During the procedure, respiratory parameters $\left(\mathrm{P}_{\max }\right.$, etCO $\left.\mathrm{C}_{2}, \mathrm{MV}\right)$ and HR were displayed continuously. The MAP was measured every two to five minutes (NIBP) or continuously (invasive blood pressure monitoring). The results of the measurements were recorded every five minutes.

Percutaneous abdominal needle decompression: Elevated abdominal pressure requiring intervention was determined from clinical signs, such as visible abdominal distension, tympanic percussion sounds, subcutaneous emphysema, and elevated inspiratory peak pressure $\left(\mathrm{p}_{\max }\right)$. The upper $\mathrm{p}_{\max }$ alarm setting was adjusted to trigger at approximately $+20 \%$ from baseline. The indication for PND was a consensus decision by the endoscopist and anesthesiologist based on those signs. For PND, a $14 \mathrm{G}$ or $16 \mathrm{G}$ cannula was inserted under sterile conditions through the abdominal wall in the right upper quadrant at least $5 \mathrm{~cm}$ below the rib cage after ensuring that the lower edge of the liver could not be palpated in this area. A catheter was left in situ for continuous venting.

Post-procedural course: Charts were assessed for length of stay in the postanesthesia care unit (PACU), postoperative requirement for invasive respirator support, unplanned admission to an intermediate or intensive care unit, and length of hospital stay. Particular attention was given to adverse events associated with POEM, including transient cervical/upper thoracic subcutaneous emphysema, aspiration, and pneumothorax.

Statistical analysis

Statistical analysis was performed using SPSS 22.0.0 (SPSS Inc., Chicago, IL, USA). Data were checked for 
normal distribution. Differences between measurement points were determined using one-way analysis of variance with repeated measures. The Tukey test was used for post hoc analysis. Differences between subgroups (PND-treated patients vs non-PND-treated patients or patients with emphysema $v s$ patients without emphysema) were analyzed with independent-samples $t$ tests. Unless otherwise stated, data are presented as means (standard deviation; SD). Ordinal data are presented as medians [interquartile range]. Categorical data are presented as percentage values calculated as (frequencies/number of valid data). A value of $P<0.05$ was considered to indicate statistical significance.

\section{Results}

Of the 175 consecutive patients who underwent POEM during the study period, two were excluded because their charts were unavailable, leaving 173 patients for further consideration. Patients' baseline characteristics, comorbidities, classification of esophageal motility disorders (Chicago Classification Criteria), ${ }^{18}$ and clinical grading of severity (Eckardt Symptom Score) ${ }^{17}$ are shown in Table 1.

The duration of general anesthesia was 120 (35) min, and the duration of the procedure was 96 (33) min. During the endoscopic procedure, $\mathrm{p}_{\max }$, etCO $2, \mathrm{MAP}$, and $\mathrm{HR}$ increased from baseline values (Table 2, columns $A$ and B). Therapeutic hyperventilation was applied to reduce the iatrogenic hypercapnia, although end-tidal $\mathrm{CO}_{2}$ levels remained elevated compared with baseline values (Table 2, columns A and B).

Of the 173 patients, $55(31.8 \%)$ were treated with PND. Their baseline respiratory and cardiovascular parameters were similar to those who did not require PND (Table 2, columns $\mathrm{C}$ and $\mathrm{E}$ ). PND-treated patients were differentiated from the non-treated patients only by their procedure-related higher $\mathrm{p}_{\max }$ (Table 2, columns D and F). Reductions in $\mathrm{p}_{\max }$ and MAP were observed following PND (Table 2, columns $F$ and G). No PND-related complications were observed.

Cervical/upper thoracic subcutaneous emphysema occurred in 49 of the 173 patients (Table 3). By the end of endoscopy, however, it had resolved sufficiently to permit immediate extubation after surgery in all but eight patients. These eight patients with persistent emphysema were brought to the PACU still intubated. The neck circumference was sequentially measured to track resolution of the cervical emphysema, and pneumothorax (if suspected) was excluded by plain chest radiography. These eight patients were extubated after ensuring a negative cuff leak test (5-25 min after PACU admission)
Table 1 Patient baseline characteristics $(n=173)$

\begin{tabular}{|c|c|}
\hline \multicolumn{2}{|l|}{ Characteristics } \\
\hline \multicolumn{2}{|l|}{ Demographics } \\
\hline Sex (male/ female) & 106/ 67 \\
\hline Age (yr) & $47.0(16.2)$ \\
\hline \multicolumn{2}{|l|}{ ASA physical status classification (grade) } \\
\hline I & $17.0 \%(29 / 171)$ \\
\hline II & $64.3 \%(110 / 171)$ \\
\hline III & $18.7 \%(32 / 171)$ \\
\hline Body mass index $\left(\mathrm{kg} \cdot \mathrm{m}^{-2}\right)$ & $25.5(4.8)$ \\
\hline Relevant co-morbidities, total & $31.2 \%(54 / 173)$ \\
\hline Coronary heart disease & $8.7 \%(15 / 172)$ \\
\hline Heart failure & $2.9 \%(5 / 171)$ \\
\hline Hypertension & $24.3 \%(42 / 173)$ \\
\hline Diabetes mellitus & $5.2 \%(9 / 173)$ \\
\hline Chronic obstructive pulmonary disease & $1.7 \%(3 / 173)$ \\
\hline Asthma & $5.8 \%(10 / 173)$ \\
\hline \multicolumn{2}{|l|}{$\begin{array}{l}\text { Chicago classification of esophageal motility } \\
\text { disorders }{ }^{18}\end{array}$} \\
\hline \multicolumn{2}{|l|}{ Achalasia } \\
\hline Type I (classic achalasia, failed peristalsis) & $20.2 \%(35 / 173)$ \\
\hline Type II (compressive achalasia) & $53.8 \%(93 / 173)$ \\
\hline $\begin{array}{l}\text { Type III (peristaltic fragments or spastic } \\
\text { achalasia) }\end{array}$ & $15.6 \%(27 / 173)$ \\
\hline \multicolumn{2}{|l|}{ Motility disorders } \\
\hline $\begin{array}{l}\text { Nutcracker esophagus } \\
\text { (hypertensive peristalsis) }\end{array}$ & $1.2 \%(2 / 173)$ \\
\hline $\begin{array}{l}\text { Jackhammer esophagus (hypercontractile } \\
\text { esophagus) }\end{array}$ & $1.7 \%(3 / 173)$ \\
\hline $\begin{array}{l}\text { Esophagogastric junction } \\
\text { outflow obstruction }\end{array}$ & $1.2 \%(2 / 173)$ \\
\hline Not classifiable* & $1.7 \%(3 / 173)$ \\
\hline Re-myotomy & $4.6 \%(8 / 173)$ \\
\hline $\begin{array}{l}\text { Eckardt symptom score }^{17} \\
{[0-12](\text { median }[\mathrm{IQR}])}\end{array}$ & $7[5-8]$ \\
\hline Dysphagia [0-3] & $3[2-3]$ \\
\hline Regurgitation [0-3] & $1[1-2]$ \\
\hline Chest pain $[0-3]$ & $1[0-2]$ \\
\hline Weight loss [0-3] & $1[0-2]$ \\
\hline
\end{tabular}

ASA = American Society of Anesthesiologists

Data are presented as mean (SD). Categorical data are presented as percentage values [calculated as: (frequencies/number of valid data)]. Ordinal data are presented as the median [interquartile range]

Dysphagia/regurgitation/chest pain were scored as follows: 0, none; 1 , occasional; 2, daily; 3 , each meal. Weight loss was scored as follows: 0 , none; $1,<5 \mathrm{~kg} ; 2,5-10 \mathrm{~kg} ; 3,>0 \mathrm{~kg}$

*Not classifiable because esophageal manometry was not available or was refused

and were discharged uneventfully to a general ward. The PACU stay, but not the hospital stay, was prolonged in patients with subcutaneous emphysema compared with 


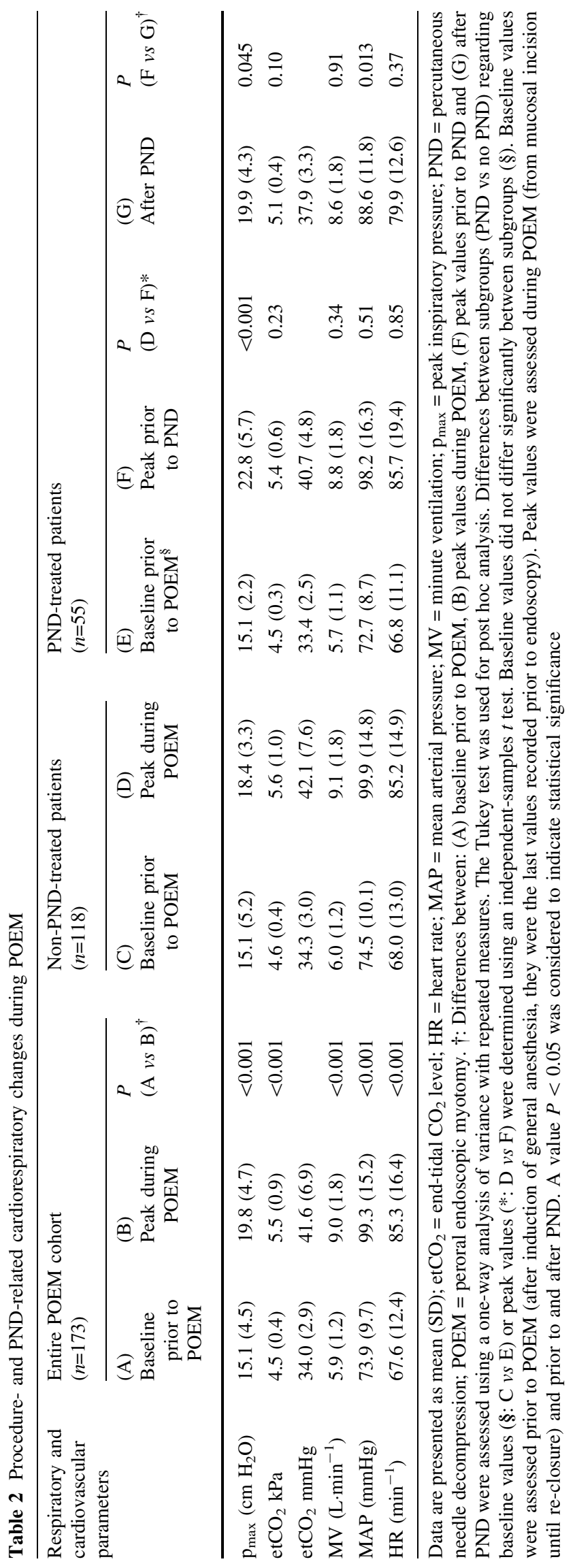


Table 3 Adverse events and outcome $(n=173)$

\begin{tabular}{ll}
\hline Events and outcomes & $\%($ no.) \\
\hline Peri-interventional adverse events & \\
Subcutaneous emphysema & $28.3 \%(49 / 173)$ \\
PND for treatment of tension & $31.8 \%(55 / 173)$ \\
capnoperitoneum & \\
Aspiration & $0.0 \%(0 / 173)$ \\
Radiological evidence of pulmonary & $0.0 \%(0 / 119)$ \\
infiltrates* & \\
Difficult airway & $5.3 \%(8 / 150)$ \\
Myocardial ischemia & $0.6 \%(1 / 173)$ \\
Pneumothorax & $0.6 \%(1 / 173)$ \\
Post-procedural recovery & \\
Length of hospital stay (days) & $4.7(2.0)$ \\
In-hospital and 30-day mortality & $(0 / 173)$ \\
Length of PACU stay (min) & $65.3(29.7)$ \\
Patients with emphysema & $74.9(34.5)$ \\
Patients without emphysema & $61.5(26.8)$ \\
Prolonged postinterventional respirator & $4.6 \%(8 / 173)$ \\
support & \\
Planned admission to an intermediate & $1.2 \%(2 / 173)$ \\
care unit & \\
\hline
\end{tabular}

Data are presented as mean (SD); Categorical data are presented as percentage values calculated as (frequencies/ number of valid data)

PND = percutaneous needle decompression; POEM = peroral endoscopic myotomy

Peri-procedural adverse events were recorded during the intervention or the early postoperative period until discharge from the postanesthesia recovery unit (PACU)

Difficult airway was defined as Cormack and Lehane $\geq 3$

*Chest plain radiography was performed in 119 of the first 121 POEM cases between the first and third postoperative day

those without it $[74.9(34.5) \min v s 61.5(26.8) \min , P=$ 0.007 and 5.0 (3.0) vs 4.6 (1.4) days, $P=0.247$, respectively]. Among the 173 patients, two had a planned admission to an intermediate care unit because of preexisting medical conditions (Table 3 ).

Other complications (Table 3) included one case of transient myocardial ischemia (inferior ST segment changes), which accompanied a brief episode of supraventricular tachycardia, and one case of pneumothorax, which was confirmed by intraoperative chest radiography and was drained during the endoscopic intervention. In the latter case, the procedure was eventually abandoned because of technical problems associated with establishing the submucosal tunnel. The patient underwent uneventful laparoscopic Heller myotomy six weeks later. None of the patients in this series experienced aspiration.

\section{Discussion}

Endoscopic therapeutic interventions have become increasingly sophisticated in recent years. The introduction of POEM marks a cornerstone of increased invasiveness in therapeutic gastrointestinal endoscopy. For the first time, an endoscopic procedure is being performed during which the integrity of the gastrointestinal tract is deliberately interrupted. During POEM, endoscopically insufflated $\mathrm{CO}_{2}$ may inadvertently track into surrounding tissues. Unlike laparoscopic surgery, however, $\mathrm{CO}_{2}$ feedback pressure regulation is not available during POEM. This situation likely contributes to the high incidence of mediastinal and cervical emphysema and capnoperitoneum, which may be considered inevitable consequences of the endoscopic intervention.

Although it is recognized that POEM poses unique anesthesia-related challenges, standardized management has yet to be established. Until now, only two small case series have been published that described anesthetic considerations for patients undergoing POEM. Neither of these reports quantified the effects of $\mathrm{CO}_{2}$ insufflation on cardiorespiratory function or the impact of therapeutic interventions such as hyperventilation or PND. ${ }^{19,20}$

In our study, MAP and HR increased during POEM. These findings should be revisited in the context of the existing evidence regarding intended pressure-regulated capnoperitoneum during laparoscopic surgery. Many studies have shown that HR, MAP, and systemic vascular resistance increase during the pressure-regulated capnoperitoneum that occurs during laparoscopic surgery. ${ }^{21-23}$ Although this hemodynamic response to capnoperitoneum is almost uniform, the underlying mechanisms appear to be multifactorial. ${ }^{21}$ It has been suggested that the MAP increase might be a direct effect of absorbed $\mathrm{CO}_{2},{ }^{24}$ mechanical vascular compression, ${ }^{21}$ sympathetic stimulation, ${ }^{23}$ and/or release of norepinephrine, ${ }^{23,25}$ vasopressin, ${ }^{22}$ renin, and aldosterone. $^{21,23}$ Perhaps the etiology of the cardiovascular responses associated with the inadvertent capnoperitoneum during POEM is similar to that associated with the intended capnoperitoneum during laparoscopic surgery.

Endoscopic $\mathrm{CO}_{2}$ insufflation during POEM has an important impact on systemic $\mathrm{CO}_{2}$ balance. We observed high systemic $\mathrm{CO}_{2}$ uptake during POEM that was difficult to counterbalance by therapeutic hyperventilation. We propose that not only peritoneal absorption of $\mathrm{CO}_{2}$, as occurs during laparoscopy, ${ }^{21}$ but also submucosal, subcutaneous, and mediastinal $\mathrm{CO}_{2}$ absorption contribute to this high $\mathrm{CO}_{2}$ uptake during POEM. 
We observed a POEM-related increase in $\mathrm{p}_{\max }$, which served as a marker of elevated intra-abdominal pressure and as a clinical indicator of the need for PND. As $\mathrm{p}_{\max }$ and MAP decreased after abdominal pressure decompression, monitoring them could be helpful for evaluating the effectiveness of PND. Percutaneous abdominal needle decompression is an established technique for treating tension capnoperitoneum secondary to iatrogenic bowel perforation during endoscopy, with established clinical indications for its implementation. ${ }^{15}$ Data supporting such clinical indications for POEM, and the effectiveness of PND during it, were heretofore not available.

Our findings show that, although insufflation-related cardiorespiratory responses are likely inevitable during POEM, they appear to be of little consequence so long as they are treated promptly and correctly. To this end, hyperventilation for treating iatrogenic hypercapnia and PND to release abdominal pressure may be considered complementary therapeutic strategies.

We found a low incidence of severe adverse events and a 30-day mortality rate of zero in our study cohort. Subcutaneous emphysema occurred in $28 \%$ of our patients, but it appeared to be transient and without relevant clinical sequelae other than slightly prolonging extubation and the PACU stay. Severe operation-related infections such as mediastinitis or peritonitis were rarely reported (approximately $0.1 \%$ ) in previous studies ${ }^{5,11}$ and were not observed in our cohort. Previous studies, however, have reported varying rates of other adverse events in patients undergoing POEM. Whereas Familiari et al. ${ }^{26}$ did not report any severe perioperative complications among 100 patients, Ren et al. ${ }^{13}$ reported incidences of subcutaneous emphysema (56\%), pneumothorax (25\%), mediastinal emphysema (29\%), hemorrhage (1\%), pleural effusion (49\%), and minor inflammation or segmental lung atelectasis $(50 \%)$ in 119 patients.

Of note, we did not observe any evidence of aspiration in our study cohort. Most patients with achalasia undergoing POEM have severe regurgitation and dysphagia. Evacuation of solid esophageal contents via esophagogastroduodenoscopy prior to POEM has been recommended. ${ }^{7,19}$ Although there is no clear evidence that this measure prevents peri-procedural aspiration, it is part of our routine preparation prior to POEM. We also strongly recommend a pre-surgery liquid diet, antacid therapy, and the use of rapid sequence induction to avoid aspiration in these unique patients.

The study did have limitations. Our data represent a single-centre experience, so caution should be taken when they are extrapolated to other institutions with variable surgical and anesthesia management strategies for these cases. Confounding variables - procedure time, mucosal incision, tunnel width, myotomy depth, sigmoid-type esophagus - represent important risk factors for gasrelated complications. ${ }^{27}$ The retrospective nature of this study is a well-recognized limitation. Importantly, patients were not randomized to blinded PND/non-PND treatment, so the differences between these two groups should be treated with appropriate caution. The study was not sufficiently powered to assess the incidence of rare, severe adverse events. The absence of these events, as reported, should also be regarded cautiously. End-tidal $\mathrm{CO}_{2}$ is only a surrogate marker for arterial $\mathrm{CO}_{2}$ partial pressure, and we likely underestimated the hypercapnia resulted from systemic uptake of $\mathrm{CO}_{2}$. Finally, the periodic recording of cardiorespiratory data is an acknowledged source of error, and the peak changes in these parameters may have been missed in some cases.

In conclusion, endoscopically insufflated $\mathrm{CO}_{2}$ during POEM may inadvertently track into surrounding tissues, causing transient cervical/upper thoracic subcutaneous emphysema, free abdominal $\mathrm{CO}_{2}$ with increased intraabdominal pressure, and high systemic $\mathrm{CO}_{2}$ uptake. These situations, in turn, can affect cardiorespiratory parameters such as increased $\mathrm{p}_{\max }$, etCO $\mathrm{CO}_{2}$ MAP, and $\mathrm{HR}$. Hyperventilation and PND can help mitigate some of these changes. Subcutaneous emphysema, which is common, may delay extubation and prolong the PACU stay.

Conflict of interest All authors state that they have no conflict of interest and no financial ties relevant to this study.

Editorial responsibility This submission was handled by Dr. Steven Backman, Associate Editor, Canadian Journal of Anesthesia.

Author contributions Benjamin Löser and Martin Petzoldt contributed substantially to all aspects of this manuscript, including the study design, data collection, statistical analysis, data interpretation, literature review, and drafting the article. Yuki Werner contributed substantially to data collection and to the conception of the manuscript. Mark A. Punke contributed substantially to statistical analysis, data interpretation, and drafting the manuscript. Bernd Saugel contributed substantially to data interpretation and drafting the article. Sebastian Haas contributed substantially to data interpretation and to reviewing the manuscript for its intellectual content. Daniel A. Reuter contributed substantially to the study design, data interpretation, and drafting the manuscript. Oliver Mann contributed substantially to data collection and drafting the article. Anna Duprée contributed substantially to data collection and to reviewing the manuscript for its intellectual content. Guido Schachschal contributed substantially to data collection, data interpretation, and reviewing the manuscript for its intellectual content. Thomas Rösch contributed substantially to reviewing the literature, the study design, data collection, statistical analysis, and data interpretation.

Funding No external funding and no competing interests are declared. The study was funded solely by institutional sources. 


\section{References}

1. Boeckxstaens GE, Zaninotto G, Richter JE. Achalasia. Lancet 2014; 383: 83-93.

2. Campos GM, Vittinghoff E, Rabl C, et al. Endoscopic and surgical treatments for achalasia: a systematic review and metaanalysis. Ann Surg 2009; 249: 45-57.

3. Pandolfino JE, Gawron AJ. Achalasia: a systematic review. JAMA 2015; 313: 1841-52.

4. Inoue $H$, Minami $H$, Kobayashi $Y$, et al. Peroral endoscopic myotomy (POEM) for esophageal achalasia. Endoscopy 2010; 42: 265-71.

5. NOSCAR POEM White Paper Committee, Stavropoulos SN, Desilets DJ, Fuchs KH, et al. Per-oral endoscopic myotomy white paper summary. Gastrointest Endosc 2014; 80: 1-15.

6. Von Renteln D, Fuchs KH, Fockens $P$, et al. Peroral endoscopic myotomy for the treatment of achalasia: an international prospective multicenter study. Gastroenterology 2013; 145: 309-11.e1-3.

7. von Renteln $D$, Inoue $H$, Minami $H$, et al. Peroral endoscopic myotomy for the treatment of achalasia: a prospective single center study. Am J Gastroenterol 2012; 107: 411-7.

8. Wei M, Yang T, Yang X, Wang Z, Zhou Z. Peroral esophageal myotomy versus laparoscopic Heller's myotomy for achalasia: a meta-analysis. J Laparoendosc Adv Surg Tech A 2015; 25: 123-9.

9. Werner YB, Costamagna $G$, Swänstrom LL, et al. Clinical response to peroral endoscopic myotomy in patients with idiopathic achalasia at a minimum follow-up of 2 years. Gut 2016; 65: 899-906.

10. Barbieri LA, Hassan $C$, Rosati R, Romario UF, Correale L, Repici A. Systematic review and meta-analysis: efficacy and safety of POEM for achalasia. United European Gastroenterol J 2015; 3: 325-34.

11. American Society for Gastrointestinal Endoscopy PIVI Committee; Chandrasekhara V, Desilets D, Falk GW, et al. The American Society for Gastrointestinal Endoscopy PIVI (Preservation and Incorporation of Valuable Endoscopic Innovations) on peroral endoscopic myotomy. Gastrointest Endosc 2015; 81(1087-100): e1.

12. Cai MY, Zhou PH, Yao LQ, Zhu BQ, Liang L, Li QL. Thoracic CT after peroral endoscopic myotomy for the treatment of achalasia. Gastrointest Endosc 2014; 80: 1046-55.

13. Ren Z, Zhong $Y$, Zhou P, et al. Perioperative management and treatment for complications during and after peroral endoscopic myotomy (POEM) for esophageal achalasia (EA) (data from 119 cases). Surg Endosc 2012; 26: 3267-72.
14. Repici A, Hassan C, Barbieri L, et al. Sa1557 safety of POEM for achalasia: systematic review of the literature. Gastrointest Endosc 2014. DOI:10.1016/j.gie.2014.05.175.

15. Chiapponi C, Stocker $U$, Körner M, Ladurner R. Emergency percutaneous needle decompression for tension pneumoperitoneum. BMC Gastroenterol 2011; 11: 48.

16. Saxena $P$, Pippenger $R$, Khashab MA. Preventing aspiration during peroral endoscopic myotomy. J Anesth 2014; 28: 959.

17. Eckardt VF. Clinical presentations and complications of achalasia. Gastrointest Endosc Clin N Am 2001; 11: 281-92, vi.

18. Bredenoord AJ, Fox M, Kahrilas PJ, et al. Chicago classification criteria of esophageal motility disorders defined in high resolution esophageal pressure topography. Neurogastroenterol Motil 2012; 24(Suppl 1): 57-65.

19. Tanaka E, Murata H, Minami H, Sumikawa K. Anesthetic management of peroral endoscopic myotomy for esophageal achalasia: a retrospective case series. J Anesth 2014; 28: 456-9.

20. Yang D, Pannu D, Zhang $Q$, White JD, Dragnov PV. Evaluation of anesthesia management, feasibility and efficacy of peroral endoscopic myotomy (POEM) for achalasia performed in the endoscopy unit. Endoscopy International Open 2015; 3: E289-95.

21. Hirvonen EA, Poikolainen EO, Pääkkönen ME, Nuutinen LS. The adverse hemodynamic effects of anesthesia, head-up tilt, and carbon dioxide pneumoperitoneum during laparoscopic cholecystectomy. Surg Endosc 2000; 14: 272-7.

22. Walder $A D$, Aitkenhead $A R$. Role of vasopressin in the haemodynamic response to laparoscopic cholecystectomy. Br J Anaesth 1997; 78: 264-6.

23. Koivusalo AM, Kellokumpu I, Scheinin M, Tikkanen I, Makisalo $H$, Lindgren L. A comparison of gasless mechanical and conventional carbon dioxide pneumoperitoneum methods for laparoscopic cholecystectomy. Anesth Analg 1998; 86: 153-8.

24. Ho HS, Saunders CJ, Gunther RA, Wolfe BM. Effector of hemodynamics during laparoscopy: $\mathrm{CO} 2$ absorption or intraabdominal pressure? J Surg Res 1995; 59: 497-503.

25. Myre K, Rostrup M, Buanes T, Stokland O. Plasma catecholamines and haemodynamic changes during pneumoperitoneum. Acta Anaesthesiol Scand 1998; 42: 343-7.

26. Familiari $P$, Gigante $G$, Marchese $M$, et al. Peroral endoscopic myotomy for esophageal achalasia: outcomes of the first 100 patients with short-term follow-up. Ann Surg 2016; 263: 82-7.

27. Wang $X$, Tan $Y$, Zhang J, Liu D. Risk factors for gas-related complications of peroral endoscopic myotomy in achalasia. Neth J Med 2015; 73: 76-81. 